\title{
Following the Astrobiology Roadmap: Origins, Habitability and Future Exploration
}

\author{
Aubrie O'Rourke ${ }^{1 \dagger^{*}}$, Angela Zoumplis ${ }^{1,2+}$, Paul Wilburn ${ }^{3 \dagger}$, \\ Michael D. Lee ${ }^{3}$, Zhi Lee ${ }^{4}$, Marissa Vecina ${ }^{4}$ and Kysha Mercader ${ }^{4}$ \\ 1J. Craig Venter Institute, La Jolla, CA, USA \\ ${ }^{2}$ Scripps Institution of Oceanography, La Jolla, CA, USA \\ ${ }^{3}$ NASA Ames Research Center, Moffett Blvd, Mountain View, CA 94035, \\ USA \\ ${ }^{4} \mathrm{UCSD}$, School of Engineering, Senior Design Group, La Jolla, CA, USA \\ *aorourke@jcvi.org †equal contribution
}

DOI: https://doi.org/10.21775/cimb.038.001

\begin{abstract}
Astrobiology asks three fundamental questions as outlined by the NASA Astrobiology Roadmap: 1. How did Life begin and evolve?; Is there Life elsewhere in the Universe?; and, What is the future of Life on Earth? As we gain perspective on how Life on Earth arose and adapted to its many niches, we too gain insight into how a planet achieves habitability. Here on Earth, microbial Life has evolved to exist in a wide range of habitats from aquatic systems to deserts, the human body, and the International Space Station (ISS). Landers, rovers, and orbiter missions support the search for signatures of Life beyond Earth, by generating data on surface and subsurface conditions of other worlds. These have provided evidence for water activity, supporting the potential for extinct or extant Life. To investigate the putative ecologies of these systems, we study extreme environments on Earth. Several locations on our planet provide analog settings to those we have detected or expect to find on neighboring and distant worlds. Whereas, the field of space biology uses the ISS and low gravity analogs to gain insight on how transplanted Earth-evolved organisms will respond to extraterrestrial environments. Modern genomics allows us to chronicle the genetic makeup of such organisms and provides an understanding of how Life adapts to various extreme environments.
\end{abstract}




\section{Introduction}

Several efforts, such as the Human Microbiome Project (HMP), the Earth Microbiome Project, and Microbes of the Built Environment (MoBE) research have contributed an understanding of the pervasiveness of the microbial world. Select microbes can survive the hyper-arid environment of Chile's Atacama Desert, the low temperatures of Antarctica, and the high radiation experienced on the exterior surfaces of the ISS. Such extreme environments found on Earth and in the outer limits of its atmosphere serve as analogs for the environments likely to be encountered in transit to and on other worlds. While we are in the early phases of hypothesizing on the nature of extraterrestrial Life, we must be particularly mindful of the potential for our Earth-evolved microbes to affect or inhabit extraterrestrial habitats (e.g. forward contamination), as we explore signatures of Life in the solar system. The goal of sending humans, deeper than ever before, into our solar system entails addressing additional questions and challenges.

The field of space biology uses phenotypic and genotypic characterization to better understand the effect the space environment has on Earthevolved organisms. In the current -omics era, we have the capacity to better investigate the questions posed by both astrobiologists and space biologists alike. Next-generation sequencing (NGS) technologies have allowed us to understand the effects that environmental conditions, like those experienced on Earth in extreme environments or outside of our atmosphere, have upon the genomes, transcriptomes, and proteomes of prokaryotic and eukaryotic populations. In this chapter, we follow the Astrobiology Roadmap (Des Marais et al., 2008) by first describing the origin of Life on Earth, and then by discussing how life evolved to survive in extreme Earth environments (Figure 1). In the final section, we present the important role Planetary Protection plays in shaping the future of space exploration and space biology research.

\section{Origins: how did Life begin and evolve?}

There are two primary theories as to how Life came to be on Earth: I) the prebiotic theory and II) the theory of panspermia. The prebiotic or primordial soup theory, contends that chemical evolution involving the CNOP elements (carbon, nitrogen, oxygen, and phosphorus) occurred in response to physical and chemical selective pressures impressed by early Earth's reducing atmosphere (Farmer et al. 2018). The primordial soup was greatly affected by the energy inputs coming from meteor impacts, volcanic eruptions, lightning, and super tides. Utilizing these energy inputs, chemical elements formed monomers through the process known as abiogenesis (Emeline et al. 2003). These monomers would later polymerize into the four major macromolecules: carbohydrates, lipids, proteins, and nucleic acids and eventually begin to self-replicate and allow for the formation of organic Life as we know it. 


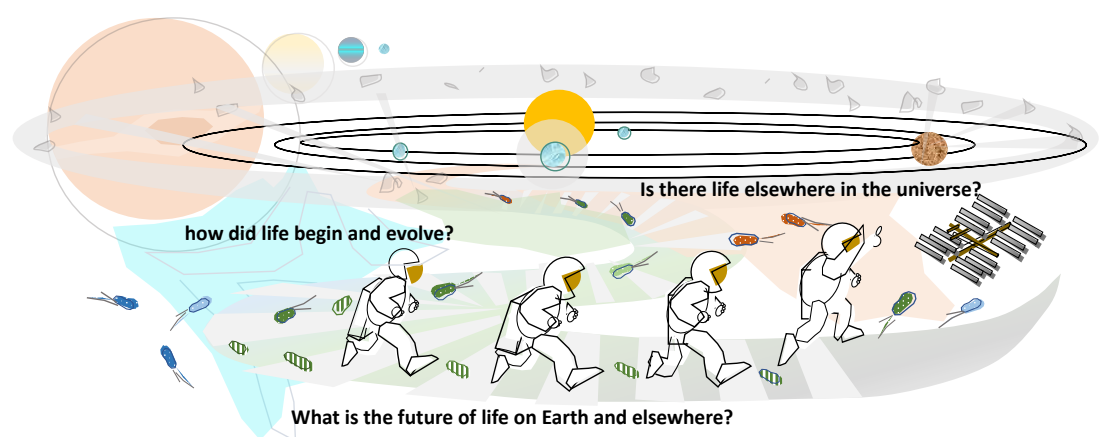

Figure 1. The Astrobiology Roadmap.

A proposed setting for the occurrence of abiogenesis is at the site of hydrothermal vents, where elements from the Earth's core could be shaped by ocean chemistry to form organic molecules (Martin et al., 2008). After millions of years of chemical evolution, circumstances may have arisen enabling a semipermeable membrane to encapsulate a self-replicating molecule, such as RNA, DNA, or possibly prion-like proteins. These progenitors of modern cells served to concentrate chemical reactions, which allowed cellular compartmentalization to continue to evolve. Then around 3.6 billion years ago, a successful combination of macromolecules within a membrane is believed to have led to, what is now known as, the Last Universal Common Ancestor (LUCA) - the cell from which all currently known biological cells arose (Koonin, 2003).

The alternative theory of panspermia contends that complex, organic macromolecules, or even possibly LUCA, was seeded to the Earth from another planet or celestial body. In our solar system, we have the four terrestrial or rocky planets closest to the sun - Mercury, Venus, Earth, and Mars; farther away are the four gas giants or Jovian planets: Jupiter, Saturn, Uranus, and Neptune. Each of these planets formed as it attracted matter into its gravitational pull through the process of accretion. The material that did not form planets such as rock, dust, and ice, instead formed the asteroids, comets, and dwarf planets. Asteroids are predominantly rocky, and mostly occupy the asteroid belt between the rocky inner planets and the outer Jovian planets. Whereas, comets are predominantly composed of ice (Lissauer,1993). In the 4.6 billion years since the accretion of our planet, Earth has experienced 5 mass extinctions punctuated by meteorite (asteroid and comets that have entered our atmosphere) impacts. These Earth- changing impacts define the geological time periods (Sleep et al. 1989). During the Hadean Period, 4.6 to 4 billion years ago (unit of time also known as Gya), the Earth and the rest of the 
inner terrestrial planets experienced a time known as the Late Heavy Bombardment - where there was an increased frequency of impact events from asteroids and other impactors (Fassett et al., 2013). Many of these, struck with enough force to cause fragments to be expelled from the planets' atmospheres. Our moon itself, formed as the result of a body estimated to be roughly the size of Mars, known as Theia, slamming into Earth (Herwartz et al., 2014).

Asteroids and comets are the two vehicles that may have helped enrich our early planet and Mars with water (Lunine et al., 2003; Raymond et al., 2004). Asteroids are also known to hold amino acids and other biomolecules (Kvenvolden et al., 1970). Meteorites have been argued to contain evidence for life by some, though others contend that their properties can arise entirely abiotically (Martel et al.,2012). Regardless of its origins, Life on Earth was able to take a foothold due to a reduction in the frequency of impacts, a sustained atmosphere and magnetosphere, and other properties of Earth, which allowed for a more stable environment for evolution. Mars, in contrast, lost its magnetic field and atmosphere (Dehant et al., 2007) relatively quickly. With the loss of this critical protection, it was no longer shielded from the Sun's UV light and radiation. In some respects, Mars could be viewed as an old Earth.

\section{Search for past life on Mars}

The exploration of Mars began with the Viking rover in 1976 then flybys by the Odyssey satellite in 2001. This continued with the lander missions which included the Opportunity rover in 2003 and later the Curiosity rover in 2011. Curiosity had the ability to drill shallow holes (5 centimeters deep), laser-blast rock surfaces, and perform mass spectrometry; yet, these efforts revealed no evidence of extant Life. However, as Curiosity surveyed the Gale Crater on Mars, it collected evidence to suggest that water once existed at the site (Martín-Torres et al., 2015). If we are to obey the Earth adage of "follow the water", as water fosters Life, we can hypothesize that at one point in the history of Mars, it may have been habitable. The layered silica sediments, as well as images of what the rocks look like, tell a story of a once wet Mars where Gale Crater was the site of an ancient spring-fed lake (Cabrol et al.,1999). The presence of silica in Gale Crater also suggested it would be an ideal location to find preserved biosignatures (Williams et al., 2013).

Additional evidence for organic Life on Mars includes the presence of carbonates in Martian dust; these carbonates are a sign of water and carbon dioxide, either past or present (Bridges et al., 2019). Carbonates can be generated by biotic processes as well as abiotic processes. On Earth, the bacterial carbonate deposits known as stromatolites and microbialites, serve as some of the oldest fossil evidence for biological Life (Nutman et al., 2016). In a recent discovery, NASA reported the presence of organic molecules in the rocks and methane in the atmosphere of Mars 
(Ten Kate, 2018). The search for Life on Mars continues. Future projects such as MAVEN (Mars Atmosphere and Volatile Evolution mission) will provide a quantitative analysis of the gases of Mars (Jakosky et al., 2015), while next-generation rovers, such as the NASA's InSight lander and the Mars 2020 rover, as well as the European Space Agency's (ESA) ExoMars program will survey the Mars lithosphere using deeper coring methods (Vago et al., 2015). The geological results may reveal signatures reminiscent of the beginnings of Life on Earth.

Our capacity to evaluate extraterrestrial Life at the molecular and polymer level continues to build. Sequencing platforms are the workhorses of targeted amplicon, metagenomic and metatranscriptomic sequencing. Further development of NGS techniques allows for nucleic acid polymerization to be sequenced with fluorescence-based and the porebased methods. In the fluorescence-based method, the sequence is read by tagging nucleotides with unique fluorophores. Alternatively, the porebased method uses an electric field and a nanometer-sized pore to read the sequence of a polymer according to how the monomers alter the electric density of the current. This pore-based technology, known as Nanopore, may be able to characterize the building blocks of extraterrestrial Life, even of a different composition. Nanopore's small footprint, roughly the size of a human finger, makes it especially suitable for transport on limited capacity payloads, and it has been used to sequence DNA on the ISS (Castro-Wallace et al., 2017). These methods have been used extensively to characterize the diversity and abundance of microbes present in an environment, the constituents of their genomes, and the genes they express. Such approaches are applied to the extreme environments found on Earth as well, and help develop our understanding of how microbes survive in extraterrestrial analog settings.

\section{Habitability: is there Life elsewhere in the universe?}

\section{Exoplanets}

The astrobiology roadmap aims to guide the exploration of the nature and distribution of habitable environments within the universe. However, to begin, a distinction should be made between the commonly thought of "habitable zone" and the concept of "habitability". Herein, the "habitable zone" refers to the concept, theorized by astrophysicist Su-Shu Huang, in which a planet must orbit a star at a distance such that the energy from the star sustains liquid water on the planet's surface (Huang, 1960) - this is often referred to as the "Goldilocks zone". The term "habitability" herein, refers to being able to sustain Life from the point of view of our current information, meaning requiring liquid water, an energy source, and conditions suitable for complex chemistry (but no stellar requirements, distance-based or otherwise). The Kepler space telescope has been a key player in identifying exoplanets (extrasolar planets) which fall in the habitable zone (Batalha et al., 2014). 
One of the most common methods for detecting exoplanets is known as the transit method, wherein an exoplanet may be detected as it passes in front of its parent star from our point of view. It is then sometimes possible to use transmission spectroscopy to gain insight into the atmosphere of the prospective exoplanet to look for compounds such as water vapor (Sing et al., 2011). There are an estimated 40 billion exoplanets within the habitable zone (Farmer, 2018). To date, the Kepler mission has identified greater than 3,000 and confirmed more than 100 in the habitable zone (Batalha, 2014). A number of these are in tidal lock and therefore experience temperature extremes on either side of the planet. It remains to be seen if Earth's life-generating features, such as liquid water, a Life-sustaining atmosphere, a radiation-shielding magnetosphere, and a UV-blocking ozone have been reproduced on any of these exoplanets.

\section{Analog environments: Adaptive strategies in cold, dry environments}

Icy moons and tidally locked exoplanets may hold microbial Life which can survive the cold. Metabolism and energy production are typically repressed in psychrotrophs (organisms that can survive at low temperatures but have optimal growth temperatures $>20^{\circ} \mathrm{C}$ ) in colder conditions, while psychrophiles (organisms with optimal growth temperatures $<10^{\circ} \mathrm{C}$ ) tend to increase nutrient acquisition, photosynthetic efficiency, and upregulate genes involved in metabolic pathways (Raymond-Bouchard et al., 2017). Low temperatures have been shown to cause increased expression in the following for both psychrotrophs and psychrophiles: lipid biosynthesis, osmoprotectants, cold shock, and antifreeze proteins (Raymond-Bouchard et al., 2017). Fatty acid desaturases help limit the increased rigidity of the cell membrane upon freeze events (Králová, 2017). The biosynthesis and transport of compatible solutes including glycine betaine, ectoine, and trehalose help to prevent water loss from cells as ice forms.

At the transcription and translation levels, a suite of molecular adaptations can help deal with the formation of secondary structures in mRNA. Many of these adaptations come with trade-offs for the cell, either as energy costs or by compromising performance in mesophilic environments. For example, the so-called DEAD-box RNA helicases are experimentally shown to induce ATP-dependent unwinding of RNA secondary structures formed during cold stress in E.coli (Cartier et al., 2010). A broad class of csp (e.g. $\operatorname{csp} A$ ) cold-shock RNA chaperones has been detected in many Bacteria (Wouters et al. 2001), and ctr (cold-responsive TRAM domain) are the small RNA binding proteins with a TRAM domain that have been proposed as putative cold-induced chaperones in some Archaea (Zhang et al., 2017). Small RNA-binding proteins (Rbps) play important roles in transcription termination, especially in cyanobacteria, and have been reported to accumulate in the wake of cold stress (Mori et al., 2003). RNA degradosomes (protein complexes built on top of RNases) have also been reported to show increased expression in the cold, presumably to recycle 
ribonucleotides from putatively secondarily structured RNAs. Chaperone and other accessory proteins also come at a cost, as protein synthesis is the most energetically costly process in the cell. Additionally, the nonplanar structure of dihydrouridine can enhance tRNA flexibility and is elevated in some psychrophilic Bacteria and Archaea (Dalluge et al., 1997).

At the protein level, ClpB and the oxidation-activated Hsp33 are chaperones that stabilize other proteins, and have also been reported as upregulated in psychrophiles (Bakermans et al. 2009; Campanaro et al., 2011; Ponder et al., 2005). In addition to using chaperones, psychrophilic enzyme homologs increase flexibility with residue substitutions that disrupt protein stability in the surrounding aqueous solution. Proteins exist in a socalled aqueous cage, created by water molecules hydrogen bonding with one another and the solutes they dissolve. Part of what stabilizes protein tertiary structures is their folding in a way that positions hydrophilic residues on the outside, allowing them to interact with the aqueous cage, while hydrophobic residues are tucked away in the core of the protein structure. Residue substitutions that disrupt this arrangement, by decreasing hydrophobicity of the core and increasing hydrophobicity of the protein outside, results in greater flexibility of the destabilized protein. Coldadapted proteins may also decrease cysteine content to avoid formation of disulfide bridges (Ásgeirsson et al., 2003). Psychrophilic genomes tend to have fewer charged and polar amino acids that can interact to form salt bridges or hydrogen bonds (Margesin et al., 2008). The amino acids in lower abundance include acidic residues and the basic arginine (also positively charged), lysine and histidine. Glycine, on the other hand, is small and non-polar. Although whole psychrophilic genomes have shown weak support for glycine enrichment, one study showed that glycine enrichment around domain active sites can increase protein flexibility without affecting residue ratios (Feller, 2013).

At a cellular level, two hallmark stories for cold adaptation deal with maintenance of membrane fluidity and freezing prevention. Lower temperatures are usually associated with increased unsaturated fatty acid (UFA) content and decreased saturated fatty acid (SFA) to UFA ratio (Mock et al., 2002; Morgan-Kiss et al., 2006; Valledor et al., 2013). This maintains membrane fluidity and provides an electron sink (in the form of UFA) in cold, photoinhibitive conditions. Interestingly, in most organisms UFA are synthesized by reversible desaturation of SFA, which must be made first. The advantage is that the SFA:UFA ratio is easily adjustable. In contrast, a few cold specialists have evolved de novo synthesis of UFA (Morgan-Kiss et al., 2006). By avoiding mandatory SFA synthesis, the de novo pathway may be more efficient at producing UFA at the cost of having a responsive SFA:UFA system. These represent alternate metabolic strategies for thermal adaptation, such that species adapted to constant cold would exhibit the efficient de novo pathway, while species exposed to variable 
temperatures would benefit from the less efficient but reversible standard pathways.

\section{Evaluating analog environments}

Locations on our planet which approach the limits of currently understood Life, serve as analogs to the early Earth, Mars, other icy worlds in our solar system, and plausible exoplanets. Quantifying the biological potential or habitability of candidate planets, moons, and asteroids is the first among equal goals of space exploration (Hubbard et al., 2002) central to NASA objectives (Des Marais et al., 2008). Characterization of extreme environments on Earth has been giving us many abiotic (environmental), biotic (genetic traits) and bioenergetic (reaction rates) insights. Each insight helps to parameterize a working definition of habitability, mostly aiming to constrain the search to key components - exemplified by "follow the water" and "follow the energy" narratives. Those approaches are rightfully useful, especially in scenarios where information available for distant exoplanets is restricted to chemical and perhaps isotopic composition.

Water is required for all known Life, and presence of liquid water on a planet's surface was classically recognized as a prerequisite for Life (Kasting et al., 1993) helping to usher in the "follow the water" guideline. Presence of liquid water has been the principal motivation for an interest in Europa and Enceladus, moons of Jupiter and Saturn respectively, and the recent discovery of water on the Moon is fueling a renewed interest in establishment of a lunar base (Milliken et al., 2017). Subsequent research included other abiotic factors, such as raw materials, a livable $\mathrm{pH}$ and temperature, and availability of light or chemical energy to drive biochemical processes - but water remains a necessary condition (Hoehler, 2007; Jones et al., 2010; Knoll et al., 2006; Tosca et al., 2008). On Mars, water exists as ice at the polar regions and in the subsurface, with the rest of the planet extremely dry and devoid of Life. In the following section, we will explore two examples of Mars analogs found here on Earth. One is the Atacama Desert which draws parallels to the arid Martian environment, and the second is the Dry Valleys of Antarctica from which we hope to learn about the ancient fluvial systems on Mars.

\section{Analog environments: Atacama Desert, Chile}

The Atacama Desert offers multiple analog conditions for Mars, as well as our Earth's Moon. It is the most ancient (90 My) and driest desert (Hartley et al, 2002; Houston et al., 2003). The ancient age of its constant environment, together with local geology, resulted in the accumulation of compounds that give Atacama's soils Mars-like properties. The hyper-arid interior of the Atacama lies at the end of a long aridity gradient, with little variation in temperature. At the dry end of that gradient, life persists in patchy endolithic communities, where photosynthesis is limited by the minimal persistence of water into daylight hours (Davilae $t$ al., 2016; Warren-Rhodes et al., 2006). These outposts for life in the Atacama interior 
are characterized by hygroscopic, or deliquescent, materials - materials that can absorb moisture from air. Deliquescent salts, including ignimbrite (Wierzchos et al., 2013), calcite or calcium carbonate (Crits-Christoph et al., 2016a) sodium chloride (Davila et al., 2010), and gypsum (Robinson et al., 2015), or calcium sulfate (Cámara et al., 2016), have been implicated in supporting habitats for endolithic cyanobacteria and a cohort of heterotrophic prokaryotes (Catling et al., 2010; Davila et al., 2008, 2010; Warren-Rhodes et al., 2007; Wierzchos et al., 2013, 2015; Wierzchos et al., 2006; Wierzchos et al., 2012). However, the Atacama is famous for its perchlorate deposits. Similarly, Mars soils are also rich in perchlorates. Catling et al used in silico modeling, which suggests that in both places perchlorates could be a result of photochemistry and ozone interacting with soil salts (Catling et al., 2010). While perchlorates can also be hygroscopic, their high oxidative reactivity provides additional challenges to survival.

One way of looking at habitability is through a biological fitness landscape. Organisms exist in fitness landscapes, dependent upon their traits, which process the environment in ways that make the environment habitable. These organismal traits are, in simplest form, often inferred descriptively through characterizing organisms or observing associations between traits and habitats. With the advent of high-throughput DNA sequencing, the associations are frequently gene-centric. Indeed, continuing discoveries of extremophiles have demonstrated the extent of habitability, and investigation of the metabolic diversity enabling this habitability has followed (Seckbach et al.,2010). Sampling of hyper-arid environments, including the Atacama, has revealed a few hallmark organisms, their community dynamics, and their metabolic potential. Members of the genus Chroococcidiopsis were found several millimeters below the crust surface (Wierzchos et al., 2006) and inside hygroscopic rocks (Warren-Rhodes et al., 2006). These primary producers support a cohort of heterotrophs in the Archae and Bacteria domains (Warren-Rhodes et al., 2006, 2007; Wierzchos et al., 2006).

Warren-Rhodes et al used molecular methods to investigate intra-genus diversity of the Chroococcidiopsis morphotype, with phylogenetic clades showing sampled-site specificity (Warren-Rhodes et al., 2007). Subsequent research used amplicons and shotgun metagenomics to reveal community dynamics, and assemble genes and complete genomes from organisms found in the Atacama (Crits-Christoph et al., 2016b; Crits-Christoph et al., 2016a; Wierzchos et al., 2015, 2012). Characterized organisms were shown to have a metabolic repertoire with putative features to prevent desiccation, carry out vital processes with limited water, resist UV damage, enter dormancy, and efficiently re-activate metabolism during short periods of water availability (Crits-Christoph et al., 2016b; Crits-Christoph et al., 2016a; Harel, 2004). In another study, Robinson et al used multivariate analyses of $16 \mathrm{~s}$ ribosomal RNA amplicons to show trends in community composition between arid and hyper-arid sites, and identified phylotypes 
most responsible for microbial community differences and implicated air humidity as the strongest environmental (Robinson et al., 2015). Recent publications advanced a few more steps to infer adaptive strategies of sampled organisms. Crits-Christoph et al sequenced halite endoliths to reveal a simple community dominated by haloarchaea, all putatively supported by a single phylotype of cyanobacteria (Crits-Christoph et al., 2016b) (Figure 2).

In a separate publication, Crits-Christoph et al presented more nearcomplete genomes from two distinct geological sites in the Atacama, providing additional genomic information for representatives of the few dominant genera at the sampled sites - including Gloeocapsa, Thermomicrobia, Conexibacter, Microlunatus, Frankineae, and Chroociccidiopsis (Crits-Christoph et al., 2016a). For example, all organisms were enriched

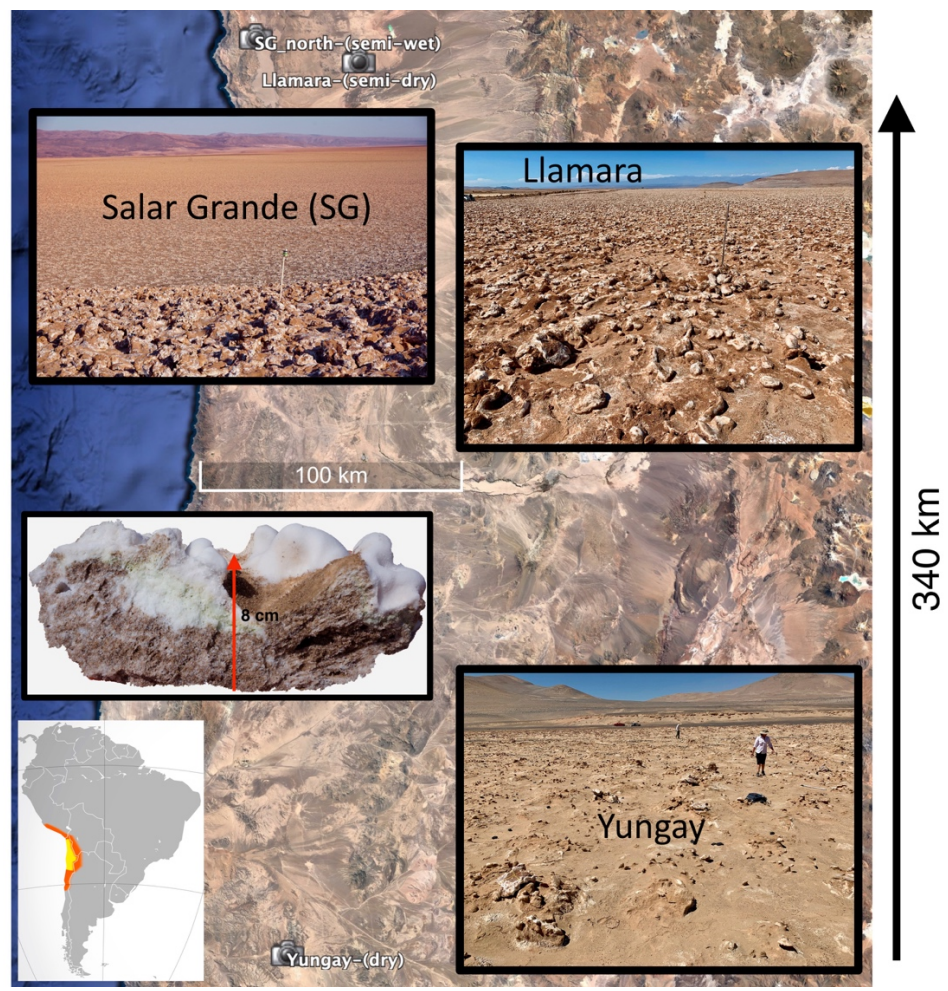

Figure 2. Halites (salt rocks) are the last habitats for life in the hyperarid Atacama Desert, Chile. Three sites illustrate the aridity gradient, refleted in halite nodule appearance. An example nodule (from SG) is shown. Note the porosity, which allows light and gas exchange. Colonized areas (partly visible green areas) are in the salt portion of the rocks. Colonization is minimal in the sparse nodules from the driest Yungay site (not shown). 
with genes involved in secondary metabolite production, which can serve as building blocks for conjugated hydrocarbons, isoprenoids, and other photoprotective compounds. These results were supported by Wierzchos et al's earlier detection of photoprotective secondary metabolites using chemical assays (Wierzchos et al., 2015), and qualitatively further described hyper-arid lifestyle potential.

These examples characterize the traits that are exhibited by organisms which are able to withstand life in the Atacama Desert and suggests that habitability is tied with unifying abiotic and biotic components. Understanding these traits alone offers a limited mechanistic understanding of organismal capabilities. It remains unclear which of the thousands of organismal traits contribute to their host's fitness along environmental gradients, including the extremes. Organisms exist in a fitness landscape, which is produced by those traits that process the environment in ways that ultimately allow that environment to be "habitable" for a given organism. Models of fitness that explicitly discover traits with environmental conditions need to be developed. This brings into focus the traits with significant impacts on success of their extremophilic hosts, and providing mechanistic insights into the minimal gene set and the limits of habitability.

\section{Analog environments: McMurdo Dry Valleys, Antarctica}

The McMurdo Dry Valleys (MDV) are considered a Martian analog environment due to extremes in aridity, high-speed winds, and low temperatures (Stanish, Nemergut, and McKnight, 2011). The use of omics tools in this environment has also led to new insights into the previously unknown abundance, diversity, and functional strategies of microbial life persisting in MDV ecosystems (Adams et al., 2014; Buelow et al., 2016; Kohler et al., 2015; Stanish et al., 2013; Van Horn et al., 2016). This cold, dry landscape consists of dynamic aquatic systems that provide unique niches for microbial communities. Although there are distinct community signatures between habitats, there is a significant degree of connectivity among glaciers, streams, lakes, and soils (Gooseff et al., 2011; Wlostowski et al., 2016). In this section we discuss MDV ecosystems in terms of their potential as Martian analogs, geochemical features, challenges to microbial life and diversity, and the functionality of their microbial communities.

\section{McMurdo Dry Valley Lakes}

Evidence that stable liquid water exists on Mars today, is supported by radar profiles of a subglacial brine pool below Mars' southern ice cap from the Mars Express spacecraft (Orosei et al., 2018). The Mars Advanced Radar for Subsurface and lonosphere Sounding (MARSIS) instrument, on the Mars Express spacecraft, is an instrument designed to scan the surface of Mars looking for evidence of liquid water. Radar profiles collected by MARSIS, between 2012-2015, displayed strong basal echoes from a $20 \mathrm{~km}$ area in Mars' southern polar ice cap, known as South Polar Layered Deposits (SPLD). The radar profiles display bright reflections that are 
indicative of an interface between ice and liquid. Further analysis of the radar data revealed a high relative dielectric permittivity $(>15)$ of the subsurface reflection which is inferred as liquid water. The liquid water is predicted to be around $1.5 \mathrm{~km}$ below the ice (Orosei et al., 2018). Data gathered yields support for the first known stable body of liquid water on Mars.

Decades of orbital imagery studies provide support for Martian hydrological activity with the identification of river channels, valley networks, and over 400 paleolake basins that potentially maintained bodies of water with unknown residence times (Cabrol and Grin, 1999; Goudge et al., 2016; Williams et al., 2001). Surface morphology analyses detect a variety of fluvial features that expose the diversity of these lakes in terms of formation (Cabrol et al., 1999). Lake basins can be closed, open, or exist in chains. Some possess outflow channels indicative of hypothesized flood events. Others include signs of erosion and deposition (Carr, 2012; Carr et al., 2010; Goudge et al., 2016). The geomorphic characterizations of these ancient lake basins, along with supporting Earth analog studies recreate possible geochemical features and physical processes that may have once controlled putative life on Mars.

The perennial ice-covered lakes of the MDV provide the closest Earth analog to recent subglacial pool discoveries, as well as the evolution of ancient paleolakes on Mars. Microbes that exist in the uniquely stratified MDV lakes survive in low-light levels, freezing temperatures, sharp chemical gradients, oxic and anoxic conditions, and chaotropic salts, which interfere with hydrogen bonding. Several lakes in the MDV are heavily studied for analogous characteristics to various freezing stages of Martian lakes (Mikucki et al., 2006).

Lake Vida is the largest lake in the MDV. The lake is in Victoria Valley which is northward of Wright Valley. Victoria Valley generally maintains lower temperatures than the southern valleys. During the austral summer, the area warms enough to produce short-lived meltwater streamflow. In early studies, Lake Vida was believed to have been completely frozen with no traces of water; however, in a later study by Doran et al. ,advancements in ground penetrating radar revealed a brine pocket $19 \mathrm{~m}$ under the ice (Doran et al., 2003). Isolated for around 2800 years, the aphotic, anoxic brine here has a temperature of $-13^{\circ} \mathrm{C}$ and a salinity of $200 \mathrm{ppt}$ (Murray et al., 2012). Further investigations of this brine system identified a bacterialdominated microbial assemblage in the isolated cryo-environment. The obstacles posed to Life in this system would be like those experienced in the subglacial systems beyond Earth. Therefore, this discovery fundamentally informs perceptions of the ability of Life to persist on icy worlds. 


\section{McMurdo Dry Valley Meltwater streams}

The meltwater streams of the MDV are an important analog to the fluvial systems that may have existed on ancient Mars (Murray et al., 2012). The valley networks in both Antarctica and Martian Noachian terrain (4.1-3.7 Gya) are comparable in surface features (Carr, 2012). Studies conducted on Martian clay mineral formation and paleolake basin stratigraphy indicate intermittent surface waters that carved valleys, transported sediments, and sustained lakes throughout the late Noachian/early Hesperian (Ehlmann et al., 2011; Goudge et al., 2016). Despite differences in nutrient availability, Martian and Dry Valley landscapes are comprised of similar basalt substrates, limited organic material, and experience long durations of dryness and freezing temperatures due to transient flow ( Doran et al., 2010).

During the austral summer, rising temperatures cause glacial melting and transient freshwater streams begin to flow, downward through the valleys, carrying alluvium while rehydrating stream beds. Temperature fluctuations of the Dry Valley meltwater streams reach anywhere from $0.1{ }^{\circ} \mathrm{C}$ to a maximum of $15{ }^{\circ} \mathrm{C}$ with daily shifts between $6^{\circ} \mathrm{C}-9^{\circ} \mathrm{C}$. Changes in temperature, flow duration, and speed are associated with rapid climate shifts making adaptations to a highly variable environment an important quality among inhabitants (Stanish et al., 2011). Life in the stream channels survives an absence of water for around 9 out of 12 months and is primarily comprised of cyanobacterial mats that harbor bacteria, eukaryotic algae, and micro-invertebrates (Adams et al., 2014; Esposito et al., 2008; McKnight et al., 1999). Throughout early and late summer, the cyanobacterial mats undergo numerous freeze-thaw cycles (Davey et al., 1992). With the onset of winter, these mats persist in a freeze-dried state until the following season (Figure 3).

\section{McMurdo Dry Valley Don Juan Pond}

Observations of dark flows on steep slopes that extend downhill recur each Mars year known as recurring slope lineae (RSL), as well as the presence of hydrated salts, are potential signs of a fleeting source of liquid water. The RSL have been linked to warm temperatures (Grimm et al., 2014). In addition, spectral data analyzed from the Compact Reconnaissance Imaging Spectrometer for Mars (CRISM) on the Mars Reconnaissance Orbiter (MRO), have indicated the presence of magnesium perchlorate, magnesium chlorate, and sodium perchlorate in four RSL locations (Ojha et al., 2015).

The atmospheric pressure on Mars confines the potential for any biologically available liquid water to low elevations where pressure may exceed $6.1 \mathrm{mbars}$ (Doran et al., 2010). Any water formed exists for a short duration before evaporating or freezing (Grimm et al., 2014). However, an incorporation of salts lowers the freezing point and evaporation rate which may increase the stability of water (Massé et al., 2016). 


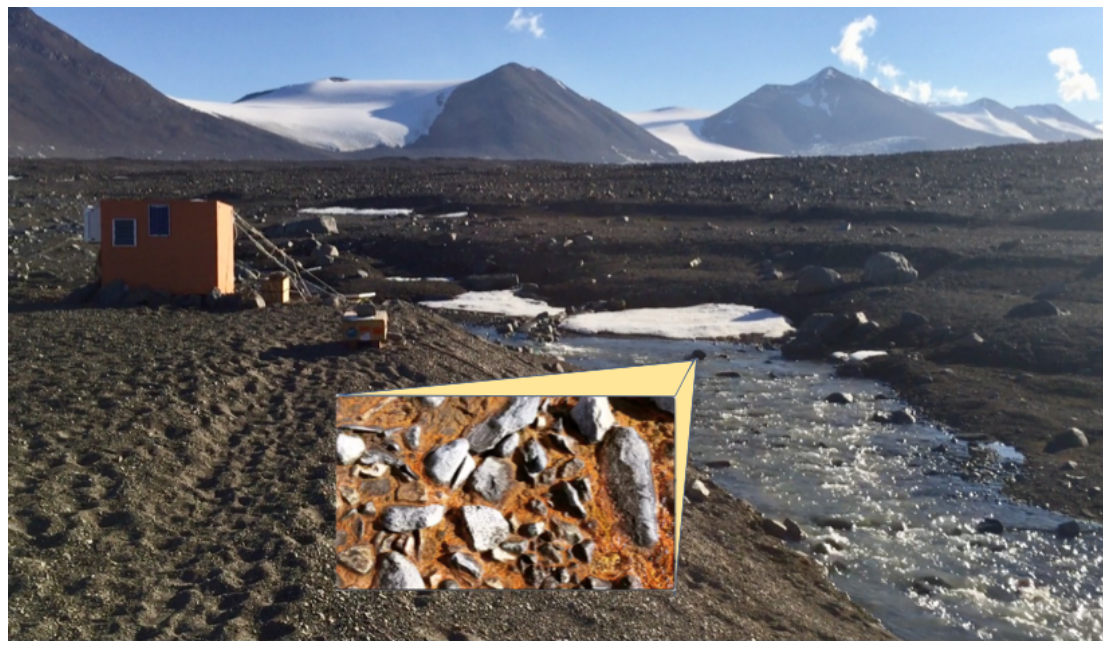

Figure 3. A gauge box set up by the Long-Term Ecological Research team to monitor water stream chemistry and hydrology of Von Guerard stream in the McMurdo Dry Valleys. Image zoom is of the cyanobacteria mats that are found in the meltwater streambeds.

Don Juan Pond (DJP) is an ice-free hypersaline pond located in the Wright Valley of the MDV. It is one of the saltiest bodies of water on Earth, comprised of $40 \%$ salt by weight. Salt in DJP is primarily (>90\%) $\mathrm{CaCl}_{2}$ (Toner, Catling, and Sletten, 2017). The high salinity ensures that the pond remains unfrozen, during the austral winters, at temperatures below $-50^{\circ} \mathrm{C}$ (Marion, 1997). The input sources for the pond are widely debated in the literature. Arguments have been made for the upwelling of a deep groundwater flow system that replenishes the brines, and also for the deliquescence of salts in the shallow subsurface (Dickson et al., 2013; Nuding et al., 2014; Toner et al., 2017). Deliquescence is the process in which salts absorb atmospheric moisture at a critical relative humidity. The salts then dissolve in the absorbed water resulting in the formation of an aqueous brine (Nuding et al., 2014). Many studies on RSL suggest deliquescence as the formation mechanism for the darkened slope streaks (Dickson et al., 2013; Gough et al., 2017). Laboratory studies on DJP salts suggest brines on Mars could be rich in $\mathrm{CaCl}_{2}$ given the melting temperature of the mixture. The unique geochemistry of this system is an important analog to the Martian subsurface and may provide clues in the ongoing investigations of RSL (Dickson et al., 2013; Mikucki et al., 2006).

DJP is an important site in the search for extremophiles and for Life that may be able to exist in the ephemeral brines of Mars. Water activity $\left(a_{w}\right)$ thresholds for life on Earth appear to be limited to an $a_{w} \geq 0.605$ (Grant, 
2004; Stevenson et al., 2015). It is uncertain whether any actively metabolizing Life exists in the DJP environment due to extremes in salt content, low fluctuating water activity $a_{w}=0.3-0.6$, and subzero temperatures. Early studies suspected the presence of microbial mats in DJP brine (Horowitz et al., 1972; Siegel et al., 1979). Several recent studies attempting to detect active life have yielded contrary results (Peters et al., 2014; Samarkin et al., 2010). A primary limitation on the existence of life in DJP is the chaotropic nature of the brine salts, which interferes with hydrogen bonding, weakens the hydrophobic effect and lends to the instability of macromolecules.

We have presented two extreme Earth environments that serve as analogs to better understand the potential for habitability in some extraterrestrial environments. However, as we look to the future of Life in other locations, we also learn a lot about the capacity of Earth-evolved organisms to continually adapt to their environments over time.

\section{Space Exploration: what is the future of life on Earth and elsewhere?}

In previous sections we were introduced to the (possibly) low-frequency event that is the emergence of Life - be it through chemical evolution on Earth or elsewhere in our galaxy or through the chance event that an asteroid with the right elements struck our planet at the right time. We have also been introduced to two extreme environments on Earth which demonstrate how the microbial world under nearly any circumstance will abound and rebound. If we consider these concepts in the context of human space travel, we begin to understand the future role humans will play in trafficking microbes. In this section we discuss Planetary Protection, which serves both as a policy and motivation for scientific investigation. Planetary Protection places humans as the custodians of our solar system and uses space biology to understand how Earth-evolved organisms will be affected by or will affect the extraterrestrial environment.

\section{Planetary Protection}

NASA complies with the Planetary Protection provisions set forth by the 1967 Outer Space Treaty. The Outer Space Treaty, which was signed by all space-faring nations in 1967, stipulates that every effort must be made to protect other worlds from biological contamination from Earth. In addition, the Earth must be protected from the potential hazards posed by extraterrestrial matter carried by a spacecraft returning from another planet or other extraterrestrial sources. Therefore, NASA has gone to great lengths to control any potential organic and biological contamination carried by spacecraft. The governing body on the regulation of interplanetary microbial contamination is NASA's Office of Planetary Protection. Now more than ever, as we travel into space with the intent to land on the surface of these other worlds, we need to consider the risk of contaminating the destination environment. The Committee on Space Research (COSPAR) has a guideline that any mission, designed to look for 
life on other worlds, must not have a probability greater than 1-in-10,000 that a single microbe carried on board will contaminate potential extraterrestrial habitats.

As a precautionary measure, space-bound instrumentation has been routinely swabbed in order to categorize and characterize any microbial hitchhikers (Crawford, 2005). Researchers have catalogued strains of bacteria that were able to survive sterilization processes in European Space Agency (ESA) clean rooms (Moissl-Eichinger, 2017; Moissl et al., 2007); similarly, microbial survivors post-sterilization have been observed in the clean rooms utilized by NASA to assemble spacecraft (Mahnert et al., 2015). The discovery of resistant microbes shows that previous methods of cleaning, such as radiation and desiccation, might not be sufficient to sterilize spacecraft. For example, Acinetobacter species are dominant members of the clean room community and have been found to be able to metabolize or biodegrade the utilized cleaning reagents such as ethanol, 2propanol, and Kleenol 30 (alkaline floor detergent). This suggests that the organisms can metabolize disinfectants, metabolizing them as a nutrient source. This may also prime the bacteria to be tolerant to the oxidative stresses associated with the low-humidity environment of the clean rooms (Mogul et al., 2018). In addition, the external surfaces of spacecrafts are found to harbor highly resilient bacterial species. It was through the EXPOSE-E mission of the European Space Agency (ESA) that researchers found that endospores mounted on the ISS could still survive by escaping exposure to radiation (hiding in cracks or being shielded by the spacecraft) (Horneck et al., 2012). These observations will be factored into design considerations in order to uphold Planetary Protection policies.

\section{Space biology and human-hosted microbes aboard the ISS}

Given that humans host millions of microorganisms, and that microbes will be an essential component of any self-sustaining food-production system, human space travel is inextricably linked to microbial communities. The field of space biology actively investigates the effects of radiation and microgravity upon microbes, fungi, plants, and animals to understand how space travel may cause them to adapt, develop differently, or change at the cellular and molecular levels. In the effort to send humans deeper into space, exhaustive research into human health in the space environment is underway in both Earth-based analogs and on board the ISS. NASA's Human Exploration Research Analog (HERA), NASA's Extreme Environment Mission Operations (NEEMO), High Seas, and other Earthbased analogs work to understand the dynamics of long duration confinement and how the body responds to stressors. The Center for the Advancement of Science in Space (CASIS) is the manager of the ISS U.S. National Laboratory, where years of space biology research has taken place and been chronicled in NASA's GeneLab Project. 
In the light of Planetary Protection, human-hosted microbes are a key element of deep-space travel that remain to be better understood. In a recently published astronaut twin study a number of genetic, immune function, metabolic and microbial differences were observed between the individual which spent a year in space and the ground control (GarrettBakelman et al., 2019). Their findings on the changes experienced in the gut microbial assemblage of the one astronaut, agreed with results from The Astronaut Microbiome Project (AMP). The AMP has characterized the gut, oral, skin, and nasal microbiomes from a cohort of astronauts before, during, and after spaceflight. This research sought to understand how these populations would change over the course of a space mission as a result of stress and altered immune function, and how the resident microbes on board the ISS might affect the astronaut microbiome and vice versa. Preliminary findings concluded that the gut microbiome does indeed change during spaceflight and in some astronauts returns to its preflight status within 60 days after returning to Earth, whereas in others it did not. It was additionally concluded that the microbiome of the ISS surfaces changes over time and this is influenced by the skin microbiota of the astronauts residing in the ISS at the associated point in time (Voorhies et al., 2016). A recent publication that details the total and viable bacterial and fungal communities associated with the ISS, provides further evidence that the microbiome of the ISS changes over time, while the dominant taxa are associated with the human microbiome and include potentially opportunistic species (Checinka Sielaff et al., 2019).

It remains to be understood how the resident microbes on board the ISS affect the astronaut microbiome, but a first step is to understand how the space environment affects the microorganisms themselves. In-flight experiments and ground-based, low-shear, modeled microgravity experiments on Escherichia coli (Ciferri et al., 1986; Kacena et al., 1999a; Kacena et al.,1997; Kacena et al., 1999b; Klaus et al., 1997; Volkmann, 1988), Bacillus subtilis (Kacena et al., 1999a; Kacena et al., 1997; Kacena et al., 1999c), Salmonella enterica (Foster and Spector, 1995), Staphylococcus aureus (Castro-Wallace et al., 2011; Castro-Wallace, 2012; Rosado et al., 2010), Pseudomonas aeruginosa (McLean et al., 2001) and Ralstonia pickettii (Mijnendonckx et al., 2013), it has been shown that bacterial morphology, growth, metabolism, gene transfer, antibiotic resistance, and infectious nature can be altered in response to the space environment (Lapchine et al., 1986; Nickerson et al., 2004; C. a Nickerson et al., 2000; Tixador et al., 1985). So far, any changes detected have primarily been ascribed to two characteristics of the microgravity environment - the reduction in hydrostatic pressure and the lower fluidshear forces (K. J. Dickson, 1991).

NASA has routinely sampled the air, surface, and water on board the ISS. This has resulted in a collection of 424 bacterial isolates, collected over 12 years and 22 missions. While not experimentally designed per se (as it is 
impossible to know how long any individual isolate was on the ISS before it was isolated, regardless of the date of isolation), this library provides one window into the effect of the microgravity and enhanced radiation experienced by resident microbes. In the air and surface samples, Staphylococcus species account for $80 \%$ and $70 \%$ of the isolates recovered in this collection, respectively. These Staphylococcus species include isolates of $S$. aureus, $S$. auricularis, S. capitis, S. cohnii, S. epidermidis, S. haemolyticus, S. hominis, S. lugdunensis, S. saprophyticus, and S. warneri - all human commensals. Species of the closely related Burkholderia and Ralstonia genera comprise $60 \%$ of the isolates collected from the water system over the 12 years. Recovered Burkholderia species include B. contaminans and B. cepacia. In general, Burkholderia species exhibit a high degree of phenotypic plasticity as they can live in soil, water (Miller et al., 2002), and the human body (Valvano, Keith, and Cardona, 2005), known to be opportunistic pathogens and are equipped for life in extreme environments (Lee et al., 2014; Lester et al., 2007) (Figure 4). Select isolates from our culture collection display the ability to inhibit Aspergillus species (Figure 4B) and exhibit the ability to lyse red blood cells (Figure 4C).

In some bacteria, the microgravity environment can affect bacterial virulence, resulting in altered pathogenicity (C. A. Nickerson et al., 2004). For instance, members of Salmonella enterica have demonstrated increased virulence when grown under modeled microgravity simulated using a high-aspect rotating vessel (C. a Nickerson et al., 2000). Whereas, $S$. aureus grown under similar modeled microgravity conditions show an increase in the transcript levels of genes involved in biofilm formation but
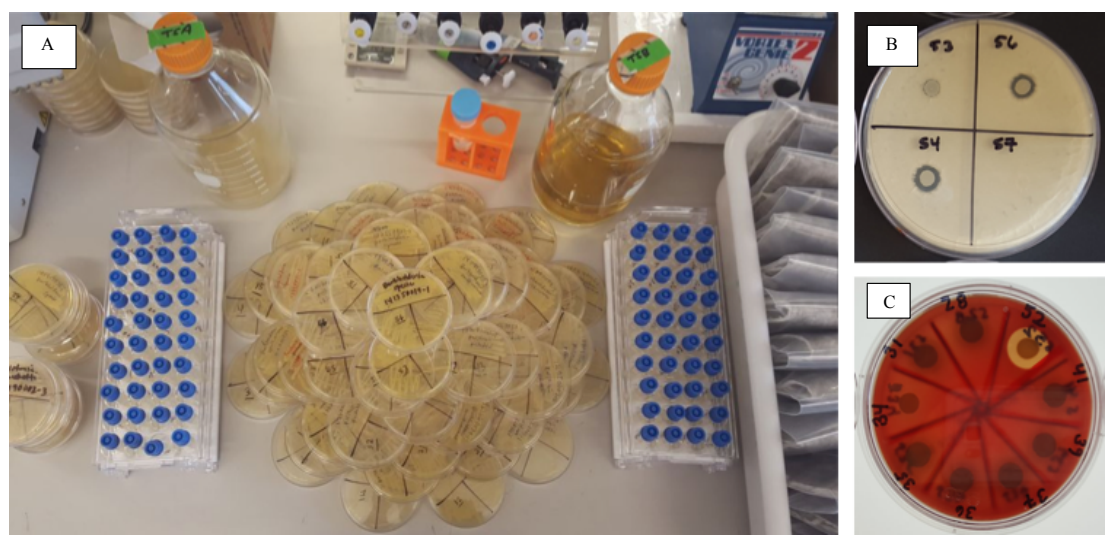

Figure 4. A. Isolates of Burkholderia and Ralstonia species cultured from the ISS potable water system. B. Select isolates display the ability to inhibit Aspergillus species (Burkholderia demonstrate zones of inhibition when spotted on agar also growing Aspergillus sp.). C. Select solates also exhibit the ability to lyse red blood cells as demonstrated by spotting the cultures on sheep's blood agar plates. 
an overall decrease in virulence-factor transcripts (Castro et al., 2011; Rosado et al., 2006). Similarly, a terrestrially-derived strain of S. aureus exposed to simulated microgravity for 24 hours exhibited a reduction in the amount of secreted alpha-toxin and hemolysin (Rosado et al., 2006). Organisms that demonstrate decreased virulence, if maintained over time, would naturally appeal to us as more suitable for a deep-space exploration scenario where a human resides in a closed-environment for months or years at a time. Space Biology is inherently a systems-biology approach where the demand for robust life-support systems will fuel the exhaustive characterization of microbes and their effect on both the crew and engineered systems. As the distance to the target increases, the odds of success decrease, and out of billions of microbial hitchhikers, some may be more appropriate for the journey than others.

\section{Conclusions}

Here we have presented only a portion of the expansive territory of Astrobiology using the Astrobiology Roadmap as our guide. We introduced the contrasting theories as to how life began on our planet and contend that perhaps it is a question best informed by observing the formation of life on another planet. However, we can still observe how life adapts as microorganisms with fast generation times reveal the mechanisms used to survive in even the harshest of environmental conditions. Understanding of microbial activity and ecology at analog sites expands our toolkit of biological signatures and expands the boundaries of which extraterrestrial environments should be targets in the search for Life in the solar system. Microbial life is able to employ a variety of mechanisms in order to satisfy their metabolic requirements, and as we set our sights on exploring other habitable worlds, we must be cognizant of the billions of microbes we will bring with us, and the potential for these microbes to survive in the extreme conditions that will be encountered. Planetary Protection aims to prevent the non-deliberate delivery of space-derived microbes to our planet (backcontamination), and the delivery of Earth-derived microbes as an invasive species to another world (forward-contamination). Due to our limited understanding of the effect that the space environment has on Earthevolved organisms, research in the field of space biology has gained traction and will continue to inform policy decisions and engineering guidelines for the future of space travel. A human presence in space is in our near future, and with it will come groundbreaking technologies and discoveries capable of improving life on Earth as well as provide us with answers as to Earth's biotic beginnings. Indeed, it seems almost science fiction when we think about the potential for Earth-evolved organisms to affect the trajectory of life on another planet, just as an intercepted asteroid may have changed the trajectory of our own.

\section{Future trends}

As genomic sequencing tools evolve and are combined with state-of-the-art analytical chemistry techniques, we will continue to improve our 
understanding of both abiotic and biotic components and refine our definitions of the requirements for habitability. Models of fitness that explicitly correlate genotypic traits with survival under specific environmental conditions need to be further developed, along with more comprehensive understandings of cellular activity and regulation. These will help to identify which particular traits have significant impacts (positive or negative) on the success of an organism and provide greater insight into the limits of habitability. Furthermore, once we can control each of the environmental and genomic factors, which influence a microbial phenotype, we can successfully plan for microbial containment. This extends to how to fulfill Planetary Protection guidelines, as well as how to keep a crew healthy and a spacecraft properly functioning, as we travel further out into our solar system.

\section{References}

Adams, B. J., Wall, D. H., Virginia, R. A., Broos, E., and Knox, M. A. (2014). Ecological biogeography of the terrestrial Nematodes of Victoria Land, Antarctica. ZooKeys. https://doi.org/10.3897/zookeys.419.7180

Alexander Voorhies, Manolito Torralba, K. M. and H. L. (n.d.). Study of the impact of longterm space travel on the Astronauts' microbiome.

Ásgeirsson, B., Nielsen, B. N., and Højrup, P. (2003). Amino acid sequence of the cold-active alkaline phosphatase from Atlantic cod (Gadus morhua). Comparative Biochemistry and Physiology - B Biochemistry and Molecular Biology. https://doi.org/10.1016/S1096-4959(03)00167-2

Bakermans, C., Bergholz, P. W., Ayala-del-Río, H., and Tiedje, J. (2009). Genomic Insights into Cold Adaptation of Permafrost Bacteria. In Permafrost Soils, Soil Biology 16. https://doi.org/ 10.1007/978-3-540-69371-0_11

Batalha, N. M. (2014). Exploring exoplanet populations with NASA's Kepler Mission. Proceedings of the National Academy of Sciences. https:// doi.org/10.1073/pnas.1304196111

Bridges, J. C., Hicks, L. J., and Treiman, A. H. (2019). Chapter 5 Carbonates on Mars. In J. Filiberto and S. P. B. T.-V. in the M. C. Schwenzer (Eds.) (pp. 89-118). Elsevier. https://doi.org/https://doi.org/ 10.1016/B978-0-12-804191-8.00005-2

Buelow, H. N., Winter, A. S., Van Horn, D. J., Barrett, J. E., Gooseff, M. N., Schwartz, E., and Takacs-Vesbach, C. D. (2016). Microbial community responses to increased water and organic matter in the arid soils of the mcmurdo dry valleys, antarctica. Frontiers in Microbiology. https://doi.org/ 10.3389/fmicb.2016.01040

Cabrol, N. A., and Grin, E. A. (1999). Distribution, Classification, and Ages of Martian Impact Crater Lakes. Icarus. https://doi.org/10.1006/icar. 1999.6191

Cabrol, N. A., Grin, E. A., Newsom, H. E., Landheim, R., and McKay, C. P. (1999). Hydrogeologic Evolution of Gale Crater and Its Relevance to the Exobiological Exploration of Mars. Icarus. https://doi.org/10.1006/icar. 1999.6099 
Cámara, B., Souza-Egipsy, V., Ascaso, C., Artieda, O., De Los Ríos, A., and Wierzchos, J. (2016). Biosignatures and microbial fossils in endolithic microbial communities colonizing Ca-sulfate crusts in the Atacama Desert. Chemical Geology. https://doi.org/10.1016/j.chemgeo. 2016.09.019

Campanaro, S., Williams, T. J., Burg, D. W., De Francisci, D., Treu, L., Lauro, F. M., and Cavicchioli, R. (2011). Temperature-dependent global gene expression in the Antarctic archaeon Methanococcoides burtonii. Environmental Microbiology, 13(8), 2018-2038. https://doi.org/10.1111/j. 1462-2920.2010.02367.x

Carr, M. H. (2012). The fluvial history of Mars. Philosophical Transactions of the Royal Society A: Mathematical, Physical and Engineering Sciences. https://doi.org/10.1098/rsta.2011.0500

Carr, M. H., and Head, J. W. (2010). Geologic history of Mars. Earth and Planetary Science Letters. https://doi.org/10.1016/j.epsl.2009.06.042

Cartier, G., Lorieux, F., Allemand, F., Dreyfus, M., and Bizebard, T. (2010). Cold Adaptation in DEAD-Box Proteins. Biochemistry, 49(12), 26362646. https://doi.org/10.1021/bi902082d

Castro-Wallace, S. L., Chiu, C. Y., John, K. K., Stahl, S. E., Rubins, H., Mcintyre, A. B. R., Alexander, N. (2017). Nanopore DNA Sequencing and Genome Assembly on the International Space Station. Scientific Reports, (December), 1-12. https://doi.org/10.1038/s41598-017-18364-0

Castro-Wallace, S. L. (2012). The Response of Staphylococcus aureus to Culture in a Low-Fluid-Shear Environment.

Castro-Wallace, S. L., Nelman-Gonzalez, M., Nickerson, C. A., and Ott, C. M. (2011). Induction of attachment-independent biofilm formation and repression of hfq expression by low-fluid-shear culture of Staphylococcus aureus. Applied and Environmental Microbiology, 77(18), 6368-6378. https://doi.org/10.1128/AEM.00175-11

Catling, D. C., Claire, M. W., Zahnle, K. J., Quinn, R. C., Clark, B. C., Hecht, M. H., and Kounaves, S. (2010). Atmospheric origins of perchlorate on mars and in the atacama. Journal of Geophysical Research E: Planets. https://doi.org/10.1029/2009JE003425

Checinska Sielaff, A., Urbaniak, C., Mohan, G. B. M., Stepanov, V. G., Tran, Q., Wood, J. M., Venkateswaran, K. (2019). Characterization of the total and viable bacterial and fungal communities associated with the International Space Station surfaces. Microbiome, 7(1), 50. https:// doi.org/10.1186/s40168-019-0666-x

Ciferri, O., Tiboni, O., Pasquale, G., Orlandoni, A. M., and Marchesi, M. L. (1986). Effects of microgravity on genetic recombination in Escherichia coli; Naturwissenschaften, 73(7), 418-421. https://doi.org/10.1007/ BF00367284

Crawford, R. L. (2005). Microbial diversity and its relationship to planetary protection. Applied and Environmental Microbiology. https://doi.org/ 10.1128/AEM.71.8.4163-4168.2005

Crits-Christoph, A., Gelsinger, D. R., Ma, B., Wierzchos, J., Ravel, J., Davila, A., DiRuggiero, J. (2016)a. Functional interactions of archaea, 
bacteria and viruses in a hypersaline endolithic community. Environmental Microbiology. https://doi.org/10.1111/1462-2920.13259

Crits-Christoph, A., Robinson, C. K., Ma, B., Ravel, J., Wierzchos, J., Ascaso, C., ... DiRuggiero, J. (2016)b. Phylogenetic and functional substrate specificity for endolithic microbial communities in hyper-arid environments. Frontiers in Microbiology. https://doi.org/10.3389/fmicb. 2016.00301

Dalluge, J. J., Hamamoto, T., Horikoshi, K., Morita, R. Y., Stetter, K. O., and McCloskey, J. A. (1997). Posttranscriptional modification of tRNA in psychrophilic bacteria. Journal of Bacteriology, 179(6), 1918-1923. https://doi.org/10.1128/jb.179.6.1918-1923.1997

Davey, M. C., and Clarke, K. J. (1992).Fine structure of a terrestrial cyanobacterial mat from Antarctica. Journal of Phycology. https://doi.org/ 10.1111/j.0022-3646.1992.00199.x

Davila, A. F., Duport, L. G., Melchiorri, R., Jänchen, J., Valea, S., de los Rios, A., Wierzchos, J. (2010). Hygroscopic Salts and the Potential for Life on Mars. Astrobiology. https://doi.org/10.1089/ast.2009.0421

Davila, A. F., Gómez-Silva, B., de los Rios, A., Ascaso, C., Olivares, H., McKay, C. P., and Wierzchos, J. (2008). Facilitation of endolithic microbial survival in the hyperarid core of the Atacam Desert by mineral deliquescence. Journal of Geophysical Research: Biogeosciences. https://doi.org/10.1029/2007JG000561

Davila, A. F., and Schulze-Makuch, D. (2016). The Last Possible Outposts for Life on Mars. Astrobiology. https://doi.org/10.1089/ast.2015.1380

Dehant, V., Lammer, H., Kulikov, Y. N., Grießmeier, J. M., Breuer, D., Verhoeven, O., ... Lognonné, P. (2007). Planetary magnetic dynamo effect on atmospheric protection of early earth and mars. Space Science Reviews. https://doi.org/10.1007/s11214-007-9163-9

Des Marais, D. J., Nuth, J. A., Allamandola, L. J., Boss, A. P., Farmer, J. D., Hoehler, T. M., ... Spormann, A. M. (2008). The NASA Astrobiology Roadmap. Astrobiology. https://doi.org/10.1089/ast.2008.0819

Dickson, J. L., Head, J. W., Levy, J. S., and Marchant, D. R. (2013). Don Juan Pond, Antarctica: Near-surface $\mathrm{CaCl}$ 2-brine feeding Earth's most saline lake and implications for Mars. Scientific Reports. https://doi.org/ 10.1038/srep01166

Dickson, K. J. (1991). Summary of biological spaceflight experiments with cells. ASGSB Bulletin: Publication of the American Society for Gravitational and Space Biology, 4(2), 151-260. Retrieved from http:// www.ncbi.nlm.nih.gov/pubmed/11537177

Doran, P. T., Fritsen, C. H., McKay, C. P., Priscu, J. C., and Adams, E. E. (2003). Formation and character of an ancient 19-m ice cover and underlying trapped brine in an "ice-sealed" east Antarctic lake. Proceedings of the National Academy of Sciences. https://doi.org/ 10.1073/pnas.222680999

Doran, P. T., Lyons, W. B., and McKnight, D. M. (2010). Life in Antarctic Deserts and other Cold Dry Environments: Astrobiological analogs. Cambridge Astrobiology. https://doi.org/10.1017/CBO9780511712258 
Ehlmann, B. L., Mustard, J. F., Murchie, S. L., Bibring, J.-P., Meunier, A., Fraeman, A. A., and Langevin, Y. (2011). Subsurface water and clay mineral formation during the early history of Mars. Nature. https://doi.org/ 10.1038/nature10582

Emeline, A. V., Otroshchenko, V. A., Ryabchuk, V. K., and Serpone, N. (2003). Abiogenesis and photostimulated heterogeneous reactions in the interstellar medium and on primitive earth: Relevance to the genesis of life. Journal of Photochemistry and Photobiology C: Photochemistry Reviews. https://doi.org/10.1016/S1389-5567(02)00039-4

Esposito, R. M. M., Spaulding, S. A., McKnight, D. M., Van de Vijver, B., Kopalová, K., Lubinski, D., Whittaker, T. (2008). Inland diatoms from the McMurdo Dry Valleys and James Ross Island, Antarctica. Botany. https:// doi.org/10.1139/B08-100

Farmer, J. D. (2018). Chapter 1 - Habitability as a Tool in Astrobiological Exploration. From Habitability to Life on Mars. (E. Grin and N. A. Cabrol, Eds.). Elsevier.

Fassett, C. I., and Minton, D. A. (2013). Impact bombardment of the terrestrial planets and the early history of the Solar System. Nature Geoscience. https://doi.org/10.1038/ngeo1841

Feller, G. (2013). Psychrophilic Enzymes: From Folding to Function and Biotechnology. Scientifica, 2013, 1-28. https://doi.org/ $10.1155 / 2013 / 512840$

Foster, J. W., and Spector, M. P. (1995). How Salmonella Survive Against the Odds. Annual Review of Microbiology. https://doi.org/10.1146/ annurev.mi.49.100195.001045

Garrett-Bakelman, F. E., Darshi, M., Green, S. J., Gur, R. C., Lin, L., Macias, B. R., ... Turek, F. W. (2019). The NASA Twins Study: A multidimensional analysis of a year-long human spaceflight. Science (New York, N.Y.), 364(6436). https://doi.org/10.1126/science.aau8650

Gooseff, M. N., McKnight, D. M., Doran, P., Fountain, A. G., and Lyons, W. B. (2011). Hydrological connectivity of the landscape of the McMurdo Dry Valleys, Antarctica. Geography Compass. https://doi.org/10.1111/j. 1749-8198.2011.00445.x

Goudge, T. A., Fassett, C. I., Head, J. W., Mustard, J. F., and Aureli, K. L. (2016). Insights into surface runoff on early Mars from paleolake basin morphology and stratigraphy. Geology. https://doi.org/10.1130/G37734.1

Gough, R. V., Wong, J., Dickson, J. L., Levy, J. S., Head, J. W., Marchant, D. R., and Tolbert, M. A. (2017). Brine formation via deliquescence by salts found near Don Juan Pond, Antarctica: Laboratory experiments and field observational results. Earth and Planetary Science Letters. https:// doi.org/10.1016/j.epsl.2017.08.003

Grant, W. D. (2004). Life at low water activity. Philosophical Transactions of the Royal Society B: Biological Sciences. https://doi.org/10.1098/rstb. 2004.1502

Grimm, R. E., Harrison, K. P., and Stillman, D. E. (2014). Water budgets of martian recurring slope lineae. Icarus. https://doi.org/10.1016/j.icarus. 2013.11.013 
Harel, Y. (2004). Activation of Photosynthesis and Resistance to Photoinhibition in Cyanobacteria within Biological Desert Crust. Plant Physiology. https://doi.org/10.1104/pp.104.047712

Hartley, A. J., and Chong, G. (2002). Late Pliocene age for the Atacama Desert: Implications for the desertification of western South America. Ge o log y. 10.1130/0091-7613(2002)030<0043:LPAFTA>2.0.CO;2

Herwartz, D., Pack, A., Friedrichs, B., and Bischoff, A. (2014). Identification of the giant impactor Theia in lunar rocks. Science. https://doi.org/ 10.1126/science. 1251117

Hoehler, T. M. (2007). An Energy Balance Concept for Habitability. Astrobiology. https://doi.org/10.1089/ast.2006.0095

Horneck, G., Moeller, R., Cadet, J., Douki, T., Mancinelli, R. L., Nicholson, W. L., ... Venkateswaran, K. J. (2012). Resistance of Bacterial Endospores to Outer Space for Planetary Protection PurposesExperiment PROTECT of the EXPOSE-E Mission. Astrobiology. https:// doi.org/10.1089/ast.2011.0737

Horowitz, N. H., Cameron, R. E., and Hubbard, J. S. (1972). Microbiology of the dry valleys of antarctica. Science (New York, N.Y.). https://doi.org/ 10.1126/science.176.4032.242

Houston, J., and Hartley, A. J. (2003). The central andean west-slope rainshadow and its potential contribution to the origin of hyper-aridity in the Atacama Desert. International Journal of Climatology. https://doi.org/ 10.1002/joc. 938

Huang, S.-S. (1960). Life-Supporting Regions in the Vicinity of Binary Systems. Publications of the Astronomical Society of the Pacific. https:// doi.org/10.1086/127489

Hubbard, G. S., Naderi, F. M., and Garvin, J. B. (2002). Following the water, the new program for Mars exploration. Acta Astronautica. https:// doi.org/10.1016/S0094-5765(02)00067-X

Jakosky, B. M., Lin, R. P., Grebowsky, J. M., Luhmann, J. G., Mitchell, D. F., Beutelschies, G., Zurek, R. (2015). The Mars Atmosphere and Volatile Evolution (MAVEN) Mission. Space Science Reviews. https://doi.org/ 10.1007/s11214-015-0139-x

Jones, E. G., and Lineweaver, C. H. (2010). To What Extent Does Terrestrial Life "Follow The Water"? Astrobiology. https://doi.org/10.1089/ ast.2009.0428

Kacena, M. A., Leonard, P. E., Todd, P., and Luttges, M. W. (1997). Low gravity and inertial effects on the growth of $E$. coli and $B$. subtilis in semisolid media. Aviation, Space, and Environmental Medicine.

Kacena, M. A., Merrell, G. A., Manfredi, B., Smith, E. E., Klaus, D. M., and Todd, P. (1999)a. Bacterial growth in space flight: Logistic growth curve parameters for Escherichia coli and Bacillus subtilis. Applied Microbiology and Biotechnology. https://doi.org/10.1007/s002530051386

Kacena, M. A., Smith, E. E., and Todd, P. (1999)b. Autolysis of Escherichia coli and Bacillus subtilis cells in low gravity. Applied Microbiology and Biotechnology. https://doi.org/10.1007/s002530051543 
Kacena, M. A., and Todd, P. (1999)c. Gentamicin: effect on E. coli in space. Microgravity Science and Technology.

Kasting, J. F., Whitmire, D. P., and Reynolds, R. T. (1993). Habitable Zones around Main Sequence Stars. Icarus. https://doi.org/10.1006/icar. 1993.1010

Klaus, D., Simske, S., Todd, P., and Stodieck, L. (1997). Investigation of space flight effects on Escherichia coli and a proposed model of underlying physical mechanisms. Microbiology. https://doi.org/ 10.1099/00221287-143-2-449

Knoll, A. H., and Grotzinger, J. (2006). Water on Mars and the prospect of martian life. Elements. https://doi.org/10.2113/gselements.2.3.169

Kohler, T. J., Stanish, L. F., Crisp, S. W., Koch, J. C., Liptzin, D., Baeseman, J. L., and McKnight, D. M. (2015). Life in the Main Channel: Long-Term Hydrologic Control of Microbial Mat Abundance in McMurdo Dry Valley Streams, Antarctica. Ecosystems. https://doi.org/10.1007/ s10021-014-9829-6

Koonin, E. V. (2003). Comparative genomics, minimal gene-sets and the last universal common ancestor. Nature Reviews Microbiology. https:// doi.org/10.1038/nrmicro751

Králová, S. (2017). Role of fatty acids in cold adaptation of Antarctic psychrophilic Flavobacterium spp. Systematic and Applied Microbiology. https://doi.org/10.1016/j.syapm.2017.06.001

Kvenvolden, K., Lawless, J., Pering, K., Peterson, E., Flores, J., Ponnamperuma, C., ... Moore, C. (1970). Evidence for Extraterrestrial Amino-acids and Hydrocarbons in the Murchison Meteorite. Nature, 228, 923. Retrieved from http://dx.doi.org/10.1038/228923a0

Lapchine, L., Moatti, N., Gasset, G., Richoilley, G., Templier, J., and Tixador, R. (1986). Antibiotic activity in space. Drugs under Experimental and Clinical Research, 12(12), 933-938. Retrieved from http:// www.ncbi.nlm.nih.gov/pubmed/3569006

Lee, Y. M., Kim, E. H., Lee, H. K., and Hong, S. G. (2014). Biodiversity and physiological characteristics of Antarctic and Arctic lichens-associated bacteria. World Journal of Microbiology and Biotechnology. https:// doi.org/10.1007/s11274-014-1695-z

Lester, E. D., Satomi, M., and Ponce, A. (2007). Microflora of extreme arid Atacama Desert soils. Soil Biology and Biochemistry. https://doi.org/ 10.1016/j.soilbio.2006.09.020

Lissauer, J. (1993). Planet Formation. Araand a, 31, 129.

Lunine, J. I., Chambers, J., Morbidelli, A., and Leshin, L. A. (2003). The Origin of water on Mars. Icarus. https://doi.org/10.1016/ S0019-1035(03)00172-6

Mahnert, A., Moissl-Eichinger, C., Berg, G., Vaishampayan, P. A., Probst, A. J., Auerbach, A. K., Miller, W. (2015). Molecular bacterial community analysis of clean rooms where spacecraft are assembled. Astrobiology. https://doi.org/10.1126/science.aad1329 
Margesin, R., Schinner, F., Marx, J. C., and Gerday, C. (2008). Psychrophiles: From biodiversity to biotechnology. Psychrophiles: From Biodiversity to Biotechnology. https://doi.org/10.1007/978-3-540-74335-4

Marion, G. M. M. (1997). A theoretical evaluation of mineral stability in Don Juan Pond, Wright Valley, Victoria Land. Antarctic Science. https:// doi.org/10.1017/S0954102097000114

Martel, J., Young, D., Peng, H.-H., Wu, C.-Y., and Young, J. D. (2012). Biomimetic Properties of Minerals and the Search for Life in the Martian Meteorite ALH84001. Annual Review of Earth and Planetary Sciences. https://doi.org/10.1146/annurev-earth-042711-105401

Martín-Torres, F. J., Zorzano, M.-P., Valentín-Serrano, P., Harri, A.-M., Genzer, M., Kemppinen, O., Vaniman, D. (2015). Transient liquid water and water activity at Gale crater on Mars. Nature Geoscience, 8, 357. Retrieved from https://doi.org/10.1038/ngeo2412

Martin, W., Baross, J., Kelley, D., and Russell, M. J. (2008). Hydrothermal vents and the origin of life. Nature Reviews Microbiology. https://doi.org/ 10.1038/nrmicro1991

Massé, M., Conway, S. J., Gargani, J., Patel, M. R., Pasquon, K., McEwen, A., Jouannic, G. (2016). Transport processes induced by metastable boiling water under Martian surface conditions. Nature Geoscience. https://doi.org/10.1038/ngeo2706

McKnight, D. M., Niyogi, D. K., Alger, A. S., Bomblies, A., Conovitz, P. A., and Tate, C. M. (1999). Dry Valley Streams in Antarctica: Ecosystems Waiting for Water. BioScience. https://doi.org/10.2307/1313732

McLean, R. J., Cassanto, J. M., Barnes, M. B., and Koo, J. H. (2001). Bacterial biofilm formation under microgravity conditions. FEMS Microbiology Letters. https://doi.org/S0378-1097(00)00549-8 [pii]

Mijnendonckx, K., Provoost, A., Ott, C. M., Venkateswaran, K., Mahillon, J., Leys, N., and van Houdt, R. (2013). Characterization of the Survival Ability of Cupriavidus metallidurans and Ralstonia pickettii from SpaceRelated Environments. Microbial Ecology. https://doi.org/10.1007/ s00248-012-0139-2

Mikucki, J. A., Priscu, J. C., Lyons, W. B., Welch, K. A., Tranter, M., and Pearson, A. (2006). Geomicrobiology of an Antarctic subglacial brine: A plausible Martian ecosystem. Geochimica et Cosmochimica Acta. https:// doi.org/10.1016/j.gca.2006.06.844

Miller, S. C. M., LiPuma, J. J., and Parke, J. L. (2002). Culture-based and non-growth-dependent detection of the Burkholderia cepacia complex in soil environments. Applied and Environmental Microbiology, 68(8), 37503758. https://doi.org/10.1128/AEM.68.8.3750-3758.2002

Milliken, R. E., and Li, S. (2017). Remote detection of widespread indigenous water in lunar pyroclastic deposits. Nature Geoscience. https://doi.org/10.1038/NGEO2993

Mock, T., and Kroon, B. M. A. (2002). Photosynthetic energy conversion under extreme conditions-l: important role of lipids as structural modulators and energy sink under $\mathrm{N}$-limited growth in Antarctic sea ice 
diatoms. Phytochemistry, 61(1), 41-51. https://doi.org/https://doi.org/ 10.1016/S0031-9422(02)00216-9

Mogul, R., Barding, G. A., Lalla, S., Lee, S., Madrid, S., Baki, R., ... Walker, J. (2018). Metabolism and Biodegradation of Spacecraft Cleaning Reagents by Strains of Spacecraft-Associated Acinetobacter. Astrobiology. https://doi.org/10.1089/ast.2017.1814

Moissl-Eichinger, C. (2017). Extremophiles in spacecraft assembly cleanrooms. In Adaption of Microbial Life to Environmental Extremes: Novel Research Results and Application, Second Edition. https://doi.org/ 10.1007/978-3-319-48327-6_10

Moissl, C., Osman, S., La Duc, M. T., Dekas, A., Brodie, E., DeSantis, T., and Venkateswaran, K. (2007). Molecular bacterial community analysis of clean rooms where spacecraft are assembled. FEMS Microbiology Ecology, 61(3), 509-521. https://doi.org/10.1111/j. 1574-6941.2007.00360.x

Morgan-Kiss, R. M., Priscu, J. C., Pocock, T., Gudynaite-Savitch, L., and Huner, N. P. A. (2006). Adaptation and Acclimation of Photosynthetic Microorganisms to Permanently Cold Environments. Microbiology and Molecular Biology Reviews. https://doi.org/10.1128/MMBR. 70.1.222-252.2006

Mori, S., Castoreno, A., Mulligan, M. E., and Lammers, P. J. (2003). Nitrogen status modulates the expression of RNA-binding proteins in cyanobacteria. FEMS Microbiology Letters, 227(2), 203-210. https:// doi.org/10.1016/S0378-1097(03)00682-7

Murray, A. E., Kenig, F., Fritsen, C. H., McKay, C. P., Cawley, K. M., Edwards, R., ... Doran, P. T. (2012). Microbial life at -13 C in the brine of an ice-sealed Antarctic lake. Proceedings of the National Academy of Sciences. https://doi.org/10.1073/pnas.1208607109

Nickerson, C. A., Ott, C. M., Wilson, J. W., Ramamurthy, R., and Pierson, D. L. (2004). Microbial Responses to Microgravity and Other Low-Shear Environments. Microbiology and Molecular Biology Reviews, 68(2), 345361. https://doi.org/10.1128/MMBR.68.2.345-361.2004

Nickerson, C. a, Ott, C. M., Mister, S. J., Brian, J., Burns-keliher, L., Pierson, D. L., and Morrow, B. J. (2000). Microgravity as a Novel Environmental Signal Affecting Salmonella enterica Serovar Typhimurium Virulence Microgravity as a Novel Environmental Signal Affecting Salmonella enterica Serovar Typhimurium Virulence, 68(6), 3147-3152. https://doi.org/10.1128/IAI.68.6.3147-3152.2000.Updated

Nuding, D. L., Rivera-Valentin, E. G., Davis, R. D., Gough, R. V., Chevrier, V. F., and Tolbert, M. A. (2014). Deliquescence and efflorescence of calcium perchlorate: An investigation of stable aqueous solutions relevant to mars. Icarus. https://doi.org/10.1016/j.icarus.2014.08.036

Nutman, A. P., Bennett, V. C., Friend, C. R. L., Van Kranendonk, M. J., and Chivas, A. R. (2016). Rapid emergence of life shown by discovery of 3,700-million-year-old microbial structures. Nature. https://doi.org/ 10.1038/nature19355 
Ojha, L., Wilhelm, M. B., Murchie, S. L., Mcewen, A. S., Wray, J. J., Hanley, J., ... Chojnacki, M. (2015). Spectral evidence for hydrated salts in recurring slope lineae on Mars. Nature Geoscience. https://doi.org/ 10.1038/ngeo2546

Orosei, R., Lauro, S. E., Pettinelli, E., Cicchetti, A., Coradini, M., Cosciotti, B., ... Seu, R. (2018). Radar evidence of subglacial liquid water on Mars. Science. https://doi.org/10.1126/science.aar7268

Peters, B., Casciotti, K. L., Samarkin, V. A., Madigan, M. T., Schutte, C. A., and Joye, S. B. (2014). Stable isotope analyses of NO2-, NO3-, and N2O in the hypersaline ponds and soils of the McMurdo Dry Valleys, Antarctica. Geochimica et Cosmochimica Acta. https://doi.org/10.1016/ j.gca.2014.03.024

Ponder, M. A., Gilmour, S. J., Bergholz, P. W., Mindock, C. A., Hollingsworth, R., Thomashow, M. F., and Tiedje, J. M. (2005). Characterization of potential stress responses in ancient Siberian permafrost psychroactive bacteria. FEMS Microbiology Ecology, 53(1), 103-115. https://doi.org/10.1016/j.femsec.2004.12.003

Raymond-Bouchard, I., and Whyte, L. G. (2017). From transcriptomes to metatranscriptomes: Cold adaptation and active metabolisms of psychrophiles from cold environments. In Psychrophiles: From Biodiversity to Biotechnology: Second Edition. https://doi.org/ 10.1007/978-3-319-57057-0_18

Raymond, S. N., Quinn, T., and Lunine, J. I. (2004). Making other earths: Dynamical simulations of terrestrial planet formation and water delivery. Icarus. https://doi.org/10.1016/j.icarus.2003.11.019

Robinson, C. K., Wierzchos, J., Black, C., Crits-Christoph, A., Ma, B., Ravel, J., ... Diruggiero, J. (2015). Microbial diversity and the presence of algae in halite endolithic communities are correlated to atmospheric moisture in the hyper-arid zone of the Atacama Desert. Environmental Microbiology. https://doi.org/10.1111/1462-2920.12364

Rosado, H., Doyle, M., Hinds, J., and Taylor, P. W. (2010). Low-shear modelled microgravity alters expression of virulence determinants of Staphylococcus aureus. Acta Astronautica, 66(3-4), 408-413. https:// doi.org/10.1016/j.actaastro.2009.06.007

Rosado, H., Stapleton, P., and Taylor, P. (2006). Effect of simulated microgravity on the virulence properties of the opportunistic bacterial pathogen Staphylococcus aureus, 1-8. Retrieved from http:// discovery.ucl.ac.uk/1350754/

Samarkin, V. A., Madigan, M. T., Bowles, M. W., Casciotti, K. L., Priscu, J. C., McKay, C. P., and Joye, S. B. (2010). Abiotic nitrous oxide emission from the hypersaline Don Juan Pond in Antarctica. Nature Geoscience. https://doi.org/10.1038/ngeo847

Seckbach, Joseph and J. Chapman, D. (2010). Red Algae in the Genomic Age. https://doi.org/10.1007/978-90-481-3795-4

Siegel, B. Z., McMurty, G., Siegel, S. M., Chen, J., and Larock, P. (1979). Life in the calcium chloride environment of Don Juan Pond, Antarctica [6]. Nature. https://doi.org/10.1038/280828a0 
Sing, D. K., Pont, F., Aigrain, S., Charbonneau, D., Désert, J. M., Gibson, N., ... Shporer, A. (2011). Hubble Space Telescope transmission spectroscopy of the exoplanet HD189733b: High-altitude atmospheric haze in the optical and near-ultraviolet with STIS. Monthly Notices of the Royal Astronomical Society. https://doi.org/10.1111/j. 1365-2966.2011.19142.x

Sleep, N. H., Zahnle, K. J., Kasting, J. F., and Morowitz, H. J. (1989). Annihilation of ecosystems by large asteroid impacts on the early Earth. Nature. https://doi.org/10.1038/342139a0

Stanish, L. F., Nemergut, D. R., and McKnight, D. M. (2011). Hydrologic processes influence diatom community composition in Dry Valley streams. Journal of the North American Benthological Society. https:// doi.org/10.1899/11-008.1

Stanish, L. F., O'Neill, S. P., Gonzalez, A., Legg, T. M., Knelman, J., Mcknight, D. M., ... Nemergut, D. R. (2013). Bacteria and diatom co-occurrence patterns in microbial mats from polar desert streams. Environmental Microbiology. https://doi.org/10.1111/j.1462-2920.2012.02872.x

Stevenson, A., Burkhardt, J., Cockell, C. S., Cray, J. A., Dijksterhuis, J., FoxPowell, M., ... Hallsworth, J. E. (2015). Multiplication of microbes below 0.690 water activity: Implications for terrestrial and extraterrestrial life. Environmental Microbiology. https://doi.org/10.1111/1462-2920.12598

Ten Kate, I. L. (2018). Organic molecules on Mars. Science. https://doi.org/ 10.1126/science.aat2662

Tixador, R., Richoilley, G., Gasset, G., Templier, J., Bes, J. C., Moatti, N., and Lapchine, L. (1985). Study of minimal inhibitory concentration of antibiotics on bacteria cultivated in vitro in space (Cytos 2 experiment). Aviation Space and Environmental Medicine, 56(8), 748-751.

Toner, J. D., Catling, D. C., and Sletten, R. S. (2017). The geochemistry of Don Juan Pond: Evidence for a deep groundwater flow system in Wright Valley, Antarctica. Earth and Planetary Science Letters. https://doi.org/ 10.1016/j.epsl.2017.06.039

Tosca, N. J., Knoll, A. H., and McLennan, S. M. (2008). Water activity and the challenge for life on early Mars. Science (New York, N.Y.). https:// doi.org/10.1126/science.1155432

Vago, J., Witasse, O., Svedhem, H., Baglioni, P., Haldemann, A., Gianfiglio, G., ... de Groot, R. (2015). ESA ExoMars program: The next step in exploring Mars. Solar System Research. https://doi.org/10.1134/ S0038094615070199

Valledor, L., Furuhashi, T., and Weckwerth, W. (2013). Systemic cold stress adaptation of Chlamydomonas reinhardtii, 1-61.

Valvano, M. A., Keith, K. E., and Cardona, S. T. (2005). Survival and persistence of opportunistic Burkholderia species in host cells, 99-105. https://doi.org/10.1016/j.mib.2004.12.002

Van Horn, D. J., Wolf, C. R., Colman, D. R., Jiang, X., Kohler, T. J., McKnight, D. M., ... Takacs-Vesbach, C. D. (2016). Patterns of bacterial biodiversity in the glacial meltwater streams of the McMurdo Dry Valleys, 
Antarctica. FEMS Microbiology Ecology. https://doi.org/10.1093/femsec/ fiw148

Volkmann, D. (1988). Microgravity and the organisms. Results of the spacelab mission D1. Acta Astronautica. https://doi.org/ 10.1016/0094-5765(88)90036-7

Voorhies, A. A., and Lorenzi, H. A. (2016). The Challenge of Maintaining a Healthy Microbiome during Long-Duration Space Missions. Frontiers in Astronomy and Space Sciences, 3(July), 1-7. https://doi.org/10.3389/ fspas.2016.00023

Warren-Rhodes, K. A., Dungan, J. L., Piatek, J., Stubbs, K., Gómez-Silva, B., Chen, Y., and McKay, C. P. (2007). Ecology and spatial pattern of cyanobacterial community island patches in the Atacama Desert, Chile. Journal of Geophysical Research: Biogeosciences. https://doi.org/ 10.1029/2006JG000305

Warren-Rhodes, K. A., Rhodes, K. L., Pointing, S. B., Ewing, S. A., Lacap, D. C., Gómez-Silva, B., McKay, C. P. (2006). Hypolithic cyanobacteria, dry limit of photosynthesis, and microbial ecology in the hyperarid Atacama Desert. Microbial Ecology. https://doi.org/10.1007/ s00248-006-9055-7

Wierzchos, J., Ascaso, C., and McKay, C. P. (2006). Endolithic Cyanobacteria in Halite Rocks from the Hyperarid Core of the Atacama Desert. Astrobiology. https://doi.org/10.1089/ast.2006.6.415

Wierzchos, J., Davila, A. F., Artieda, O., Cámara-Gallego, B., de los Ríos, A., Nealson, K. H., Ascaso, C. (2013). Ignimbrite as a substrate for endolithic life in the hyper-arid Atacama Desert: Implications for the search for life on Mars. Icarus. https://doi.org/10.1016/j.icarus. 2012.06.009

Wierzchos, J., de los Ríos, A., and Ascaso, C. (2012). Microorganisms in desert rocks: The edge of life on Earth. International Microbiology. https://doi.org/10.2436/20.1501.01.170

Wierzchos, J., DiRuggiero, J., Vïtek, P., Artieda, O., Souza-Egipsy, V., Škaloud, P., Ascaso, C. (2015). Adaptation strategies of endolithic chlorophototrophs to survive the hyperarid and extreme solar radiation environment of the Atacama Desert. Frontiers in Microbiology. https:// doi.org/10.3389/fmicb.2015.00934

Williams, R. M. E., Grotzinger, J. P., Dietrich, W. E., Gupta, S., Sumner, D. Y., Wiens, R. C., Moores, J. E. (2013). Martian Fluvial Conglomerates at Gale Crater. Science. https://doi.org/10.1126/science.1237317

Williams, R. M. E., and Phillips, R. J. (2001). Morphometric measurements of martian valley networks from Mars Orbiter Laser Altimeter (MOLA) data. Journal of Geophysical Research E: Planets. https://doi.org/ 10.1029/2000JE001409

Wlostowski, A. N., Gooseff, M. N., McKnight, D. M., Jaros, C., and Lyons, W. B. (2016). Patterns of hydrologic connectivity in the McMurdo Dry Valleys, Antarctica: a synthesis of 20 years of hydrologic data. Hydrological Processes. https://doi.org/10.1002/hyp.10818 
Wouters, J. A., Rombouts, F. M., Kuipers, O. P., de Vos, W. M., and Abee, T. (2001). Chapter 4 The role of cold-shock proteins in low-temperature adaptation. Cell and Molecular Response to Stress, 2, 43-56. https:// doi.org/10.1016/S1568-1254(01)80006-1

Zhang, B., Yue, L., Zhou, L., Qi, L., Li, J., and Dong, X. (2017). Conserved TRAM domain functions as an Archaeal cold shock protein via RNA chaperone activity. Frontiers in Microbiology, 8(AUG), 1-11. https:// doi.org/10.3389/fmicb.2017.01597 
